\title{
The Link Between Body Satisfaction and Motives in Girls
}

\author{
Natalia Barysheva ${ }^{1}{ }^{*}$ Ludmila Ozhigova $^{1}$, Natalia Lupenko ${ }^{1}$ \\ ${ }^{1}$ Kuban State University, Russia \\ "Email: baryshevapsy@gmail.com
}

\begin{abstract}
Modern realities induce a young person to be more often in the position of presenting themself in different contexts (in reality, on the Internet), which affects the problem of a person's attitude to his external appearance and raises the question of strategies for the interaction of a person with the world. Thus, the purpose of our study was to identify the characteristics of girls who are satisfied with their bodies to varying degrees in connection with motives (to achieve success and avoid failure, strive for people and fear of rejection) and self-attitude. We identified two groups: an increased level of body satisfaction ( $\mathrm{N}=40)$ and a high level of body satisfaction $(\mathrm{N}=49)$. Girls with an increased and high overall level of body satisfaction differ from each other significantly. For example, in satisfaction with the upper body, torso, lower body and skin. We note that satisfaction with certain parts of the body is associated with motives and self-attitude in girls only if it is at an increased level for them, since satisfaction with the upper part (head) is associated with the aspiration to people, satisfaction with the lower body is inversely correlated with the motive "fear of rejection " and satisfaction with the head and lower body is positively associated with self-understanding. The motivation for success is not only linked, but also influences increased skin satisfaction.
\end{abstract}

Keywords: Body satisfaction, Motive, Self-attitude.

\section{INTRODUCTION}

objective reality: part of a person's life takes place in the ordinary material world, in a specific time and space (in reality), while the other part of life finds itself in online (virtual) reality. Thus, a person evaluates themself (and is evaluated) and their appearance in situations of a real continuum in live offline interaction and at the same time constructs its appearance in the virtual world - the world of staged photographs and filmed (staged) video plots. Hence comes the great tension in evaluating and experiencing one's body and personality as a whole. A person "gets" into difficult experiences and dilemmas: to be satisfied with their appearance based on their own

and themself. On this basis they often build their own self-assessments and self-attitudes. Moreover, personal (belonging to the person themself) and social (from others) interpretation uses a "gender lens", which means external appearance always has a certain gender standard or stereotype and in priority it focuses on the
Most of the younger generation is now in conditions of a complicated socially and psychologically

assessments or rely on the opinion of others, and often virtual ones? The question of the Shakespearean hero became twice as complicated: To be or not to be in reality and in virtual reality? How to be in reality and how to "appear" in virtual reality?

These questions might be difficult for any person, but the question of the attitude to one's appearance and its presentation to others is especially acute for teenagers and adolescents. In adolescence, a person acquires an ever wider experience of social assessments of their appearance

assessment of the physical (bodily) appearance of the girl. 


\section{DISCUSSION}

One of the reasons for dissatisfaction with body size and weight is slimness as a desirable standard of beauty, especially for young women. In numerous studies authors note that most women and girls assess their appearance negatively [14]. P. Ramos, C. Moreno-Maldonado, C. Moreno indicate that both boys and girls are not satisfied with their bodies from adolescence to adulthood, but only girls in adolescence have a decline in body satisfaction [16].

The active formation of the boundaries of the body occurs in adolescence, while the assessment of one's physical appearance is more connected with the acceptance of one's body starting from adolescence [3]. In general, anxiety about a person's appearance is actualized depending on the significance and emotional assessment of the appearance, which can also lead to an increase in anxiety, depression, and determines the risk of developing eating disorders [1]. In body image research, body dissatisfaction is a key construct because of its association with unhealthy eating habits and its role as a risk factor for the onset and maintenance of eating disorders [5]. Body satisfaction has a positive effect on self-esteem, since the feeling of comfort with the body evokes generally positive feelings [6]. Concentration of attention on healthy physical appearance and on physical appearance in general can distract a person's attention from their internal senses, which can lead to difficulties in achieving the desired state of subjectively experienced well-being [10]. The choice of certain life goals corresponds to a certain perception of body image: in one study, the internal life goal "health" in adolescent girls was associated with an improvement in body image, while the external goal of the image (image, financial success) was associated with a more negative body image [8]. In another study, overall self-esteem and resilience were the determining factors for behavior towards one's body [9].

As a result, in the context of the gender interpretation of the problem of assessing a person's appearance, we can say that the study of body satisfaction for girls is a more urgent problem, since, despite the expansion of gender stereotypes, girls continue to pay more attention to the design of their corporeality with both makeup and more radical cosmetic procedures, diets and physical transformations.

\subsection{Review of current research}

What and who influences the formation of personal body satisfaction? According to Thompson's triangular influence model, the ideals of beauty are reinforced and transmitted by the following sociocultural influences: peers, parents and the media, which in turn is mediated by two factors: the internalization of the ideals of appearance and comparison of appearance. We assume that if a person assimilates the ideals of beauty in appearance (those depicted by the media or supported by parents) with which one cannot live and/or live habitually and participates in comparing appearance (for example, with peers), this can create body image problems such as body dissatisfaction [18].

Parental attitudes can affect both overall body satisfaction and individual parts, as well as formulate some gender standards, while criticism of each parent can have a different effect on body satisfaction. Thus, T.V. Keisevich and E.V. Zinovieva revealed that for girls from 17 to 24 years old, the main conflict zone is the waist, chest, hips, buttocks, the shape features of which can be associated with typical ideas about the "female figure". Inconsistencies in these categories cause a certain degree of frustration [2]. When studying parental comments on the level of body satisfaction in two age groups (18-23 years old and 24-28 years old), we noted that criticism from the mother negatively affects the body satisfaction of younger girls, while criticism from the father affects satisfaction with the body among the older group [4].

A more open, harsh, and direct assessment of peers can have a direct impact on youth concerns about appearance [19]. Lilac Lev-Ari et al found that of all social comparisons, the feeling that a best friend or sister is thinner than you is the most detrimental to body ideal in women aged 18 to 42 [11]. C. Matera et al found that peer teasing is directly correlated with increased body dissatisfaction, while peer opinions and talks influenced body dissatisfaction and desire to keep a diet in girls aged 15-19 through social comparison and internalization. [12]. E.Taniguchi and A. S. E. Hubbard found a direct correlation between the comparison of appearance and dissatisfaction with the body in girls who were confident that they would achieve their ideal. However, this relationship was not significant for girls who were not confident in achieving their ideal [17].

The influence of the media is also characterized by interesting features. It was noted that the main motivation for using the Facebook social networking site is to satisfy the need for self-presentation. [7]. Earlier studies show that if a person compares their figure with images that are attractive to them over the media, this increases the motivation for selfimprovement and for improving physical fitness [15]. An experimental study by J. Park showed a decrease in the level of body satisfaction after creating a virtual figure (respondents underwent a three-dimensional scan of the body). Respondents with lower extent of body satisfaction noted a greater interest in weight control, while the male part of the group had an intention to go in for sports [13]. 
Thus, the interaction of a person with society and the influence exerted on them show that the assessment of parents, peers and the media, which also becomes a determining aspect of the formation of personality motives and self-attitude, is an important factor in the formation of body satisfaction. Thus, parents and peers and the experience of interaction with them play an important role in the formation of a strategy of relationship with people (striving for people or avoiding people), the formation of attitudes towards activities (striving for success or avoiding failure) and the formation of self-attitude.

\section{METHOD}

We believe that there is a connection between motives and satisfaction with the body or its individual parts, and we also believe that individual motives can influence satisfaction. The study involved 100 girls from 17 to 22 years old, students of the Kuban State University of Krasnodar.

We used the following methods: A scale for assessing the level of satisfaction with the body and individual parts (upper part or head, torso, lower part, skin, hair, height) by O.A. Skugarevsky.

Methodology "Motivation for success" and "Motivation for avoiding failure" by T. Ehlers.

"Questionnaire of Affiliation" for the study of two personality motives, the aspiration for acceptance by the people (DA) and the fear of rejection (SB) by A. Mehrabian.

Test questionnaire "Self-attitude" by V.V. Stolin and S.R. Panteleev This version of the questionnaire allows us to identify such aspects as integral selfattitude, self-esteem, autosympathy, expected attitude from others, as well as scales aimed at studying the severity of attitudes towards internal actions towards the subject's self, particularly, self-confidence, attitude of others, self-acceptance, self-leadership , self-blame, self-interest and self-understanding.

Author's questionnaire. The respondents were asked to answer the questions: "How often do you visit various social platforms?" and "How often do you post your photo or video with you on your page on the social platform?" (answer options: "daily", "several times a week", "less than once a week"), "What social platforms do you visit?" (distribute platforms by frequency of visit).

Data processing was carried out in Excel and SPSS Statistics 22.0.

\section{RESULTS AND DISCUSSION}

As a result of mathematical processing of the results obtained by the methods, we revealed that the data lend themselves to a normal distribution in the surveyed sample (Shapiro-Wilk test) $\mathrm{w}=0.961364(0.96 \%$ probability of error). Parametric processing methods, Student's t-test, Spearman's correlation were applied.

Let us describe the results. According to the methodology that reveals the level of satisfaction with the body and its individual parts by O.A. Skugarevsky, the sample according to the general level of satisfaction was divided into those who predominantly have an increased (40 people) and a high (49 people) level of satisfaction. A small part of the respondents had an average level (6 people) and a lower level (5 people). Thus, most girls are quite highly satisfied with their bodies.

Since we formed small groups with not high degree of representativeness during the study, we decided to analyze the data of two groups with an increased (40 people) and high (49 people) overall level of body satisfaction. These groups differ significantly (t-test = $10.984, \mathrm{p}<0.05)$. Further, for the convenience of data presentation, let us designate girls with an increased level of satisfaction as group 1, and girls with high body satisfaction as group 2.

Differences in satisfaction with hair and height between groups of girls are not significant. Thus, the differences between girls are significant not only in assessing overall satisfaction with the body, but also in satisfaction with individual parts.

Further, in the selected groups according to the level of body satisfaction, we identified data for two motives: "motivation for success" and "motivation for avoiding

Table 1. Data on significant differences between group 1 and group 2

\begin{tabular}{|l|c|c|c|c|c|}
\hline \multirow{2}{*}{} & \multicolumn{2}{|c|}{ Group 1 } & \multicolumn{2}{c|}{ Group 2 } & \multirow{2}{*}{ t-test, $p<0.05$} \\
\cline { 2 - 5 } & M & SD & M & SD & -7.266 \\
\hline Uprso body & 25.6 & 4.3 & 32 & 2.9 & -8.814 \\
\hline Lower body & 30.5 & 3.6 & 38.2 & 3.1 & -12.927 \\
\hline Skin & 24.7 & 3.7 & 33.3 & 2.6 & -2.862 \\
\hline
\end{tabular}

Note: M - mean, SD - standard deviation. 
failure" (note: M - mean value, SD - standard deviation). Group 1 had an average level of motivation for success $(\mathrm{M}=15.27, \mathrm{SD}=4.27)$ and an average level of motivation for avoiding failures $(\mathrm{M}=14.2, \mathrm{SD}=$ $2.25)$; group 2 has an average level of motivation for success $(\mathrm{M}=16.31, \mathrm{SD}=4.18)$ and an average level of motivation for avoiding failures $(\mathrm{M}=14.87, \mathrm{SD}=$ 4.24), thus, girls with increased and high levels of body satisfaction have average motivation to achieve success and average motivation to avoid failure can indicate a moderate hope of success with an average level of risk

When interpreting the data from the A. Mehrabian's affiliation questionnaire of indicators of the severity of the motives "aspiration to be accepted by the people around" (DA) and "fear of being rejected" (FR) in the selected groups of body satisfaction, it was noted that group 1 had a high level of aspiration for acceptance (Avg. $=120.4, \mathrm{M}=117.5$ ) and a low level of fear of rejection $($ Avg. $=129.4, \mathrm{M}=131)$; group 2 showed a low level of aspiration for acceptance by others (Avg. $=118.24, \mathrm{M}=119$ ) and a high fear of rejection (Avg. $=121.5, \mathrm{M}=115$ ) (note: Avg. is the average value, $\mathrm{M}$ is the median). Thus, girls with a high level of body satisfaction tend to be accepted by others and not be afraid of rejection, while girls with high body satisfaction are not particularly eager to be accepted by others and are afraid of being rejected.

Analysis of data on the self-attitude of the individual (questionnaire "Self-attitude" by V.V. Stolin and S.R. Panteleev) among respondents with increased and high levels of body satisfaction allowed us to reveal insignificant differences between the groups. Girls with increased (group 1) and high body satisfaction (group 2) were found to have (Note: M - median, SD Standard deviation):

- a high level of global self-attitude $(\mathrm{M}=16.4, \mathrm{SD}$ = 4.6; $\mathrm{M}=16.8, \mathrm{SD}=4.6)$, respectively, self-esteem $(\mathrm{M}=8.6, \mathrm{SD}=2.8 ; \mathrm{M}=8.6, \mathrm{SD}=2.7)$, autosympathy $(\mathrm{M}=8.6, \mathrm{SD}=2.4 ; \mathrm{M}=8.8, \mathrm{SD}=2.8)$, self-interest $(\mathrm{M}$ $=6.3, \mathrm{SD}=1.6 ; \mathrm{M}=6.3, \mathrm{SD}=1.6)$, self-guidance $(\mathrm{M}$ $=4, \mathrm{SD}=1.5 ; \mathrm{M}=4, \mathrm{SD}=1.4)$;

- the average level on the scales of self-confidence $(\mathrm{M}=4.4, \mathrm{SD}=1.8 ; \mathrm{M}=4.3, \mathrm{SD}=1.6)$ and self-interest $(\mathrm{M}=5.7, \mathrm{SD}=1.4 ; \mathrm{M}=6.3, \mathrm{SD}=1.6)$;

- low level of expected attitude from others $(\mathrm{M}=$ 9.4, $\mathrm{SD}=2.5 ; \mathrm{M}=9.3, \mathrm{SD}=2.3$ ), attitude of others $(\mathrm{M}$ $=5.2, \mathrm{SD}=1.7 ; \mathrm{M}=5.2, \mathrm{SD}=1.5)$, self-acceptance $(\mathrm{M}$ $=4.8, \mathrm{SD}=1.7 ; \mathrm{M}=4.9, \mathrm{SD}=1.7)$, self-accusation $(\mathrm{M}=4.5, \mathrm{SD}=1.5 ; \mathrm{M}=4.2, \mathrm{SD}=1.7)$, selfunderstanding $(\mathrm{M}=2.7, \mathrm{SD}=1.5 ; \mathrm{M}=2.8, \mathrm{SD}=1.5)$. According to the data, we note that groups with different levels of satisfaction are similar in selfattitude.
During the survey we revealed social networks that respondents use and how much time they spend on being online. Girls of both groups predominantly use social platforms daily: group 1 - 95\% (38 people), group $2-98 \%$ (48 people). Most of the girls post photos on their pages less than once a week: group 1 - 98\% (39 people), group $2-83 \%$ (41 people). In group 2, $14 \%$ (7 people) post photos several times a week. The majority of girls most often visit social platforms that allow users to share personal information (interests, hobbies, music, place of work and study, etc.), photos, the ability to correspond, particularly - "Vkontakte" and "Instagram": group 1 - 95\% (38 people), group 2 - 95\% (47 people).

About half of the girls most often use messengers (Whatsapp and Telegram), the main purpose of which is to keep people on contact via messages, calls, and visual design - the ability to set a photo: group 1 - 38\% (15 people), group $2-51 \%$ (26 people). A small part of the respondents of both groups also noted the frequent use of Twitter, Facebook, Youtube and TikTok. Thus, the majority of the girls use social platforms that involve a certain degree of self-presentation. However, photos are not shared on an ongoing basis. At the intermediate stage of the study, we indicate the following conclusions:

- the groups of girls with an increased general level of satisfaction with their bodies differ significantly from girls with high general satisfaction with their bodies, as well as in satisfaction with the upper body, torso, lower part and skin, which may indicate that the phenomenon of body satisfaction itself is ambiguous, and that even a small difference with a sufficient level of satisfaction can be associated in different ways with other experiences or personality traits;

- girls with increased and high general body satisfaction are characterized by a simultaneous moderate hope of success and an average level of risk;

- girls with an increased level of body satisfaction tend to be accepted by others and not be afraid of rejection, and girls who have high body satisfaction do not seek acceptance by others and are very afraid of being rejected by others. We set ourselves the task of checking whether these characteristics are related to the degree of body satisfaction or not in the stage of correlation analysis;

- the features of self-attitude in girls of the two groups differ insignificantly. Girls with a sufficiently high body satisfaction correspond to a high level of global self-attitude, self-esteem, self-interest, autosympathy, self-leadership, and a weak expression of self-acceptance, self-accusation, self-understanding, expected attitude from others and attitude of others. 
Table 2. Correlation analysis data between satisfaction with individual body parts, motives and components of self-attitude

\begin{tabular}{|l|c|c|c|}
\hline \multirow{2}{*}{ Motives } & \multicolumn{3}{|c|}{ Increased satisfaction } \\
\cline { 2 - 4 } & Upper body & Lower body & Skin \\
\hline The motive of striving for people & $.379^{\star}$ & - & - \\
\hline Fear of being rejected & - & $-.389^{\star}$ & $-289^{\star}$ \\
\hline Motivation for success & - & - & - \\
\hline Self-understanding & $.387^{\star}$ & $.387^{\star}$ & \\
\hline
\end{tabular}

Note: $\ll^{*} »-\mathrm{p} \leq 0.05$.

Next, we will designate the results of the correlation study. Significant correlations were found only in girls with an overall high level of satisfaction (group 2).

According to the identified correlations, we carried out a linear regression analysis. We found that only the motive for achieving success has a significant effect on increased skin satisfaction $(\beta=0.342, \mathrm{t}=2.493$, sig $=$ $0.016)$

Thus, a fairly high satisfaction with the upper part (head), that is, with the part of the body that is primarily responsible for identification and self-presentation is associated with the aspiration to people. A possible increase in lower body satisfaction can reduce the fear of being rejected by others (and vice versa). It is interesting that with a possible increase in satisfaction with the head or lower body, the attitude towards selfunderstanding will positively change (and vice versa). The motivation for success is not only linked, but also influences increased skin satisfaction.

\section{CONCLUSIONS}

Based on the work of other researchers, we came to the conclusion that body satisfaction is a complex phenomenon that affects a person's relationship with themself and with the world around them. The main agents of influence on body satisfaction (parents, peers, media) also participate in the formation of relationships with oneself and others; self-attitude and motives in relation to society and in relation to activity are such meaningful characteristics of a person.

Girls with increased and high general levels of body satisfaction differ from each other significantly, as well as in satisfaction with the upper body, torso, lower body and skin, however, satisfaction with height and hair is approximately at the same level.

Girls with an increased overall level of body satisfaction tend to be accepted by others and not be afraid of rejection, while girls who are highly satisfied with their bodies have a low desire to be accepted by others and face great fear of rejection by others.
Significant differences in body satisfaction for this sample do not imply a difference in motivation to achieve success and to avoid failure, as well as a difference in the self-attitude of girls.

The overwhelming majority of all girls most often use social platforms and messengers that allow posting various information about themselves, including photos. However, if all girls with an increased level of body satisfaction post photos less than once a week, then a small part of respondents with high overall body satisfaction noted that they post photographs several times a week.

Only increased satisfaction with certain body parts correlates with motives and components of self-attitude in girls. We can conclude that satisfaction with body parts is associated with motives and self-attitude in girls only if it is at an increased level in them. In our study, only the motive for achieving success is not only related, but also significantly affects increased skin satisfaction.

\section{AUTHORS' CONTRIBUTION}

The theoretical significance of the results obtained by the authors lies in the fact that, in the context of clarifying studies on the influence of gender socialization on personality, the connection between motives and satisfaction with the body or its individual parts in modern girls of 17-22 years old has been proved. We managed to identify and concretize individual motives that can affect body satisfaction in girls with different levels and content of satisfaction with their physical (bodily) appearance. It has been empirically confirmed that the correlation of satisfaction with certain body parts with motives and components of self-attitude in girls is observed only if there is an increased satisfaction with the body. The applied aspect of the research results can be deployed within the framework of the practical activities of a consultant psychologist, when it is necessary to clarify the development of a consultative strategy in relation to the correction of the personality's relationship with 
themself and with the world in the context of experiencing one's body.

\section{REFERENCES}

[1]. C.L. Pop, Body mass index and body image anxiety in a sample of undergraduate students Physical Education objectives in 21st century, 46(12) (2018) 1744-1745. DOI: https://doi.org/10.15561/20755279.2018.0204B. A

[2]. P. Ramos, C. Moreno-Maldonado, C. Moreno, F. Rivera, The Role of Body Image in Internalizing Mental Health Problems in Spanish Adolescents: An Analysis According to Sex, Age, and Socioeconomic Status, Front. Psychol, 10 (2019) $1-20$.

DOI: https://doi.org/10.3389/fpsyg.2019.01952T. A

[3] I.S. Morozova, K.N. Belogay, The problem of body image in the context of developmental psychology, Society: sociology, psychology, pedagogy 7(51) (2018) 40-45. DOI: https://doi.org/10.24158/spp.2017.8.8

[4] V.A. Labunskaya, E.V. Kapitanova, Students' concern and satisfaction with their appearance as predictors of self-assessments of its components and characteristics. Russian Psychological Journal Vol. 1 (2016) 167-183. DOI: https://doi.org/10.21702/rpj.2016.1.14

[5] S. Chen, T. Jackson, D. Dong et al., Effects of Palatable Food Versus Thin Figure Conflicts on Responses of Young Dieting Women, Front. Psychol $10 \quad$ (2019) 1-5. DOI: https://doi.org/10.3389/fpsyg.2019.01025

[6] J.G. Fernández-Bustos, Á. Infantes-Paniagua, R. Cuevas et al., Effect of Physical Activity on SelfConcept: Theoretical Model on the Mediation of Body Image and Physical Self-Concept in Adolescents, Frontiers Psychology 10 (2019) 111.

DOI: https://doi.org/10.3389/fpsyg.2019.01537

[7] S. Liimakka, Healthy appearances - distorted body images? Young adults negotiating body motives. Journal of Health Psychology 19(2) (2013) 230-241. DOI: https://doi.org/10.1177\%2F1359105312468189R

[8] M. Hernández-López, A. Antequera-Rubio, M. Rodríguez-Valverde, Implicit Attitudes to Female Body Shape in Spanish Women With High and Low Body Dissatisfaction, Front. Psychol 10 (2019) 1-12. DOI: https://doi.org/10.3389/fpsyg.2019.02102
[9] B.S. Izydorczyk, M. Rąba, K. Sitnik-Warchulska, Resilience, self-esteem, and body attitude in women from early to late adulthood, Health Psychology Report 6(3) (2018) 193-206. DOI: https://doi.org/10.5114/hpr.2018.74698

[10] C.E. Walker, E.G. Krumhuber, S. Dayan et al., Effects of social media use on desire for cosmetic surgery among young women, Current Psychol, 2019. DOI: https://doi.org/10.1007/s12144-01900282-1

[11] T.A. Keisevich, E. V. Zinovieva, Family attitudes towards the appearance and attitude of young women to their physical self, Scientific research of graduates of the Faculty of Psychology, St. Petersburg State University 1 (2013) 102-108. Retrieved from: http://www.psy.spbu.ru/uploads/science/sci_resea rches/journal_sci_research-2013.pdfL

[12] R. Biolcati, G. Mancini, P. Villano, And yet I'm an adult now. The influence of parental criticism on women's body satisfaction/dissatisfaction during emerging adulthood, International journal of adolescence and youth Vol. 25 (2020) 599-608 DOI:

https://doi.org/10.1080/02673843.2019.1699433

[13] H.J. Webb, M.J. Zimmer-Gembeck, A.M. Waters et al., "Pretty Pressure" From Peers, Parents, and the Media: A Longitudinal Study of AppearanceBased Rejection Sensitivity.

[14] L. Lev-Ari, I. Baumgarten-Katz, A.H. Zohar Show Me Your Friends, and I Shall Show You Who You Are: The Way Attachment and Social Comparisons Influence Body Dissatisfaction, European eating disorders review 22(6) (2014) DOI:

https://doi.org/http://dx.doi.org/10.1002/erv.2325

[15] C. Matera, A. Nerini, C. Stefanile The role of peer influence on girls' body dissatisfaction and dieting, European review of Applied Psychology 63 (2013) 67-74. DOI: https://doi.org/10.1016/j.erap.2012.08.002

[16] E. Taniguchi, A.S. Ebesu Hubbard, Effects of physical appearance social comparisons and perceived attainability of an ideal body on body dissatisfaction and weight-management behaviors among young japanese women Japanese psychological research, 2019, pp. 1-14. DOI: https://doi.org/10.1111/jpr.12264

[17] R. Grieve, E.J. March, Watkinson, Inauthentic self-presentation on facebook as a function of vulnerable narcissism and lower self-esteem. Computers in Human Behaviour 102 (2020) 144- 
150.

DOI:

https://doi.org/10.1016/j.chb.2019.08.020

[18] C. Peng, T. Wua, Y. Chena et al. Comparing and modeling via social media: The social influences of fitspiration on male instagram users' work out intention, Computers in Human Behaviour 99, (2019) 156-167. DOI: https://doi.org/10.1016/j.chb.2019.05.011

[19] J. Park, The effect of virtual avatar experience on body image discrepancy, body satisfaction and weight regulation intention, Cyberpsychology: Journal of Psychosocial Research on Cyberspace 12(1) (2018) 1-12. DOI: https://doi.org/10.5817/CP2018-1-3 